\title{
Hydroxylated Polybrominated Diphenyl
}

\section{Ether}

National Cancer Institute

\section{Source}

National Cancer Institute. Hydroxylated Polybrominated Diphenyl Ether. NCI Thesaurus.

Code C125230.

Hydroxylated metabolites of polybrominated diphenyl ether (PBDE)-based flame retardants. PBDEs are being phased out of use because of their environmental persistence and potential hormone-disrupting effects in humans. In addition to the potential toxicity of $\mathrm{OH}-\mathrm{PBDEs}$ in humans, $\mathrm{OH}$-PBDE exposure may also disrupt oxidative phosphorylation. 